\title{
MODEL-BASED ASSESSMENT OF LONGITUDINAL DYNAMIC PERFORMANCE AND ENERGY CONSUMPTION OF HEAVY HAUL TRAIN ON LONG-STEEP DOWNGRADES
}

\author{
Jin $\mathrm{SHI}^{1^{*}}$, Shujing $\mathrm{REN}^{2}$, Mengran $\mathrm{ZHANG}^{3}$ \\ ${ }^{1,2}$ School of Civil Engineering, Beijing Jiaotong University, China \\ ${ }^{3}$ China Railway Engineering Consulting Group Co., Ltd., China
}

Received 3 June 2017; revised 3 August 2017; accepted 15 November 2017

\begin{abstract}
Longitudinal dynamics performance and energy consumption of heavy haul train should be considered in the design of heavy haul railway profile of long-steep downgrades. A quantitative analytical tool is developed to assess the longitudinal dynamic performance and energy consumption of heavy haul trains with large axle loads on grades with different longitudinal profiles, including a longitudinal dynamic model of the train and a method of calculating the energy consumption during the operation of heavy haul train. The model is then preliminarily validated by the data of coupler force collected in two comprehensive tests. Finally, the proposed analytical tool is used to assess the designed longitudinal track profile of a long-deep downgrade segment of the central south heavy haul railway of Shanxi (China).
\end{abstract}

Keywords: heavy haul train, longitudinal dynamics, long-steep downgrades, cyclic braking, energy consumption.

\section{Introduction}

Heavy haul transportation is the main direction of development for railway freight transportation in China and the world. In recent years, heavy haul railways constructed in China need to pass through perilous mountainous areas, so tracks with steep grades are often applied to overcome the difference in terrain elevation. The operational modes, such as traction and braking, of heavy haul train on steep grades not only result in longitudinal, impulsive train motion, but also alter the operational energy consumption; therefore, in the design of longitudinal track profile, not only the engineering investment should be considered, but the influence of the longitudinal profile on the operation of heavy haul train should also be considered.

Air brake and the buffering model are essential in the longitudinal dynamics model to simulate the process of braking. Some researches have been done on the longitudinal dynamics for the reference. The paper by Murtaza (1993) have developed railway air brake simulation by using empirical equations and predicted theoretical brake models. Pugi et al. (2008) have proposed simulation models of the pneumatic plant of the International Union of Railways (UIC) railway brake including libraries of pneumatic submodels. A freight car air brake system simulation model based on airflow dynamics and function principle of the " 120 " control valve is established which shows good consistence with the experiment results (Wei, Lin 2009). Piechowiak (2009) created separate partial models with different levels of accuracy taking into account airwave phenomena. Various experimental studies were carried out on their own and other test stands to verify numerical models, determine the parameters and create relatively complete models of the rail brake system (Piechowiak 2010). The train air brake system mode was integrated into the train longitudinal dynamics study that focuses on the locomotive automatic brake valve and vehicle distribution valve model (Wei et al. 2017). The paper by Afshari et al. (2013) focused on the integration of a model of a train's air brake and a non-linear model of a train's dynamics.

Three types of wagon connection coupling systems including autocouplers with standard draft gears, autocouplers with draft gears with wedge unlocking features and the traditional drawhook buffer system were evaluated (Cole, Sun 2006). Paper by Wu et al. (2017) compared three types of draft gears with different damping mechanisms: friction, polymer and friction-polymer. The paper

*Corresponding author. E-mail: jshi@bjtu.edu.cn 
by $\mathrm{Wu}$ et al. (2014a) reviewed current techniques in dynamics modelling of friction draft gears to provide a starting point that can be used to improve existing or develop new models to achieve more accurate force amplitude and pattern predictions. An advanced explicit dynamic modelling approach (Wu et al. 2015) with all components of the draft gear and their geometries considered for friction draft gears has been proposed and the conventional twostage (loading and unloading) working process of the friction draft gear was detailed as a four-stage process.

According to the above method, some papers have integrated longitudinal dynamics model. The paper by Belforte et al. (2008) presented an analysis of heavy freight train dynamics and the proposed methodology combined a new numerical model designed for the longitudinal dynamics of the whole trainset. The paper by Pugi et al. (2011) describes a full model of the pneumatic plant and buffers and draw gears as well as a mechanical model that may be mono-dimensional or tri-dimensional for simulating and optimizing freight wagons composition rules. The longitudinal dynamics model of heavy-haul trains, air brake model and draft gear model used in the Longitudinal Train Dynamics (LTDs) were established (Chang et al. 2017). The paper by Wu et al. (2016) discusses numerical solvers, vehicle connection systems, air brake systems, wagon dumper systems and locomotives, resistance forces and gravitational components, vehicle in-train instabilities, and computing schemes.

Based on the LTDs, scholars proposed methods about energy consumption and how to reuse energy. A new technology named Train Dynamics and Energy Analyser/ train Simulator (TDEAS) has been developed to perform detailed whole trip LTDs and energy analyses (Wu et al. 2014b). The paper by Sun et al. (2014) studied the energy used by heavy haul trains and the amount of energy that can be generated from dynamic braking of these trains using the CRE-LTS software package. Conti et al. (2015) proposed an innovative integrated procedure in the Matlab Simulink environment to optimise LTDs and traction and braking manoeuvres in terms of both energy and wear. The paper by Lebedevas et al. (2017) proposed the experimental and mathematical modelling increase the energy efficiency and reduce fuel consumption from diesel engines of locomotives via the main lines of the Lithuanian railway network.

However, a lack of research is noted in the existing literature on how the longitudinal profile of heavy haul railway affects the operational energy consumption and longitudinal dynamic behaviour of train. In order to provide a quantitative analytical tool for assessing the lon- gitudinal dynamic performance and energy consumption of heavy haul trains with large axle loads on grades with different longitudinal profiles and improve the design of heavy haul railway, a longitudinal dynamic model of heavy haul train with large axle load is constructed based on the current engineering practice in China, and a method of calculating the energy consumption during the operation of heavy haul train is proposed. The model is then preliminarily validated by the data of coupler force measured in the comprehensive tests for heavy haul trains running on the Beijing-Guangzhou railway and the central south heavy haul railway of Shanxi, and the procedure is introduced of predicting the longitudinal dynamic performance and energy consumption of a train running under the conditions of uphill traction and downhill cyclic braking. Finally, the proposed model and procedure is used to assess the design of longitudinal track profile of a longdeep downgrade segment of the central south heavy haul railway of Shanxi.

\section{The simulation models}

\subsection{Longitudinal dynamic model of heavy haul train}

The model proposed in this paper adopts the HXD1 locomotive and the C96 vehicle with axle load of $30 \mathrm{t}$.

\subsubsection{Kinetic equations}

In studying the longitudinal dynamics of train, the lateral and vertical motions can be neglected, and only the longitudinal degree of freedom is considered. The train is assumed to be a discrete mass system consisting of a plurality of rigid bodies (locomotives and vehicles) connected by elastic elements (coupler buffer device), as shown in Figure 1.

According to the D'Alembert's principle, the differential equations governing the motion of the train are established as follows:

$$
m_{i} \cdot \ddot{x}_{i}=S_{i}-S_{i+1}+\omega_{0 i}+F_{1}+B_{i}+D_{1}+P_{i},
$$

where:

$$
\begin{aligned}
& S_{i}=S_{i}\left(\dot{q}_{i}, q_{i}\right) ; \\
& \omega_{0 i}=\omega_{0 i}\left(\dot{x}_{i}, x_{i}\right) ; \\
& F_{1}=F_{1}\left(\dot{x}_{1}\right) ; \\
& B_{i}=B_{i}\left(\dot{x}_{i}, t\right) ; \\
& D_{1}=D_{1}\left(\dot{x}_{1}, t\right) ; \\
& P_{i}=P_{i}\left(x_{i}\right),
\end{aligned}
$$

where: $i$ is the grouping number of vehicles; $m_{i}$ is the mass

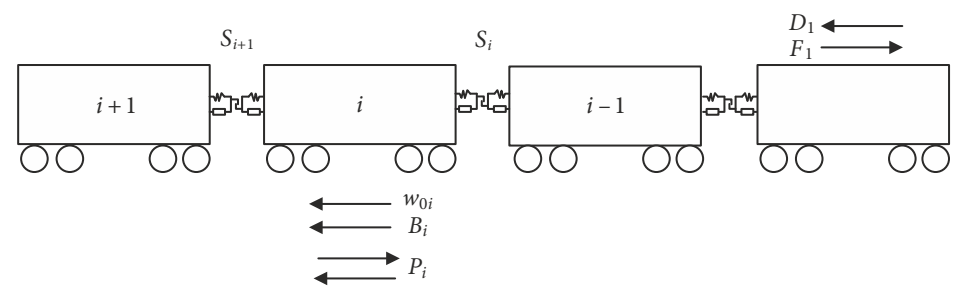

Figure 1. Discrete-mass system model of the train 
of locomotive or vehicle [t]; $S_{i}$ and $m_{i} S_{i+1}$ are the maximum longitudinal force (coupler force) between the $i$-th and $(i+1)$-th vehicles $[\mathrm{kN}] ; \omega_{0 i}$ is the basic resistance of locomotive or vehicle $[\mathrm{kN}] ; P_{i}$ is gradient resistance $[\mathrm{kN}]$; $F_{1}$ is the traction force $[\mathrm{kN}] ; B_{i}$ and $D_{1}$ are the air braking force $[\mathrm{kN}]$ and locomotive electric braking force $[\mathrm{kN}]$, respectively, and they cannot coexist with $F_{i} ; x_{i}, \dot{x}_{i}$ and $\ddot{x}_{i}$ are the absolute displacement, velocity, and acceleration of the locomotive or vehicle $[\mathrm{m}],[\mathrm{m} / \mathrm{s}]$ and $\left[\mathrm{m} / \mathrm{s}^{2}\right]$, respectively; $q_{i}$ and $\dot{q}_{i}$ are the relative displacement and velocity between two adjacent vehicles $[\mathrm{m}]$ and $[\mathrm{m} / \mathrm{s}]$, respectively; $t$ is the braking time [s].

\subsubsection{Characteristics of air brake system}

In the proposed vehicle model, the 120-type brake is used. In the simulation of the air brake system, 4 key parameters are required: the brake shoe pressure $K$, air pressure in the brake cylinder $p_{z}$, number of brake shoes per vehicle $n_{k}$, and frictional coefficient of brake shoe $\varphi_{k}$. The braking force acting on each vehicle can be expressed as:

$$
B=K \cdot \varphi_{k} \cdot n_{k}
$$

where: $B$ is the braking force for each vehicle $[\mathrm{kN}]$.

The brake shoe pressure of each brake shoe $K$ can be expressed as:

$$
K=\frac{\frac{\pi}{4} \cdot d_{z}^{2} \cdot p_{z} \cdot \eta_{z} \cdot \gamma_{z} \cdot n_{z}}{n_{k} \cdot 10^{6}}
$$

where: $\pi$ is the circumference diameter ratio, which is approximated as $3.1416 ; d_{z}$ is the radius of brake cylinder $[\mathrm{mm}] ; p_{z}$ is the air pressure in the brake cylinder [kPa]; $\eta_{z}$ is the calculated transmission efficiency of the basic braking device; $\gamma_{z}$ is the braking leverage ratio; $n_{z}$ is the number of brake cylinders; $n_{k}$ is the number of brake shoes.

For the simulated HXD1 locomotive, the diameter of brake cylinder is $178 \mathrm{~mm}$, the transmission efficiency is 0.87 , the braking leverage ratio is 2.85 , and the number of brake cylinders is 16 . In each brake, 2 high-friction synthetic brake shoes are installed. For the $\mathrm{C} 96$ vehicle, the diameter of brake cylinder is $254 \mathrm{~mm}$, the transmission efficiency is 0.9 , the braking leverage ratio is 4.85 , and the number of brake cylinders is 2 .

Pressure reduction of $140 \mathrm{kPa}$ in the train brake pipe is used in regular train braking, and smaller pressure reduction of $50 \mathrm{kPa}$ is used in cyclic braking. Figures $2 \mathrm{a}$ and $2 \mathrm{~b}$ show the variation of pressure in the brake cylinder corresponding to the amount of pressure reduction in the train brake pipe.

In this paper, high-friction composite brake shoe is adopted in the model, and the frictional coefficient between the brake shoe and brake pad is:

$$
\varphi_{k}=0.41 \cdot \frac{K+200}{4 \cdot K+200} \cdot \frac{v+150}{2 \cdot v+150}
$$

where: $K$ is the pressure $[\mathrm{kN}]$ of brake shoe (or brake pad) acting on the wheel (or brake disc) $[\mathrm{kN}] ; v$ is the running speed of the train during braking $[\mathrm{km} / \mathrm{h}]$. a)

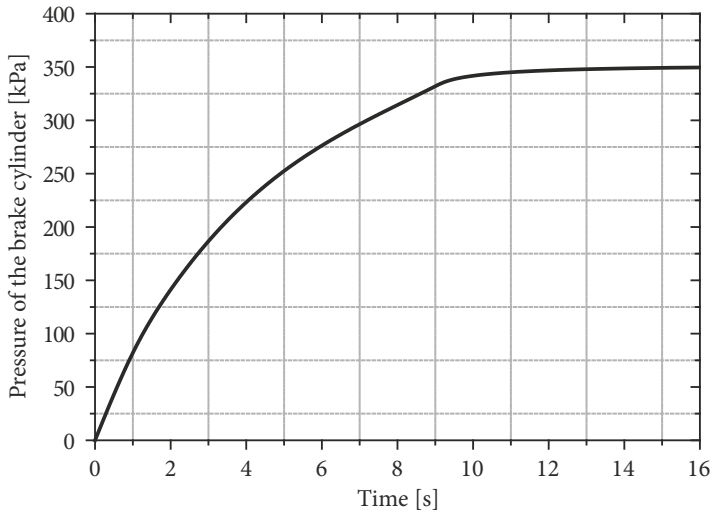

b)

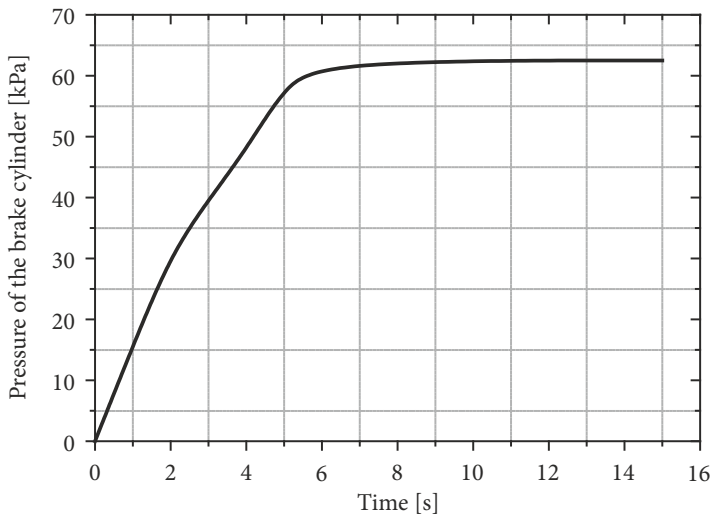

c)

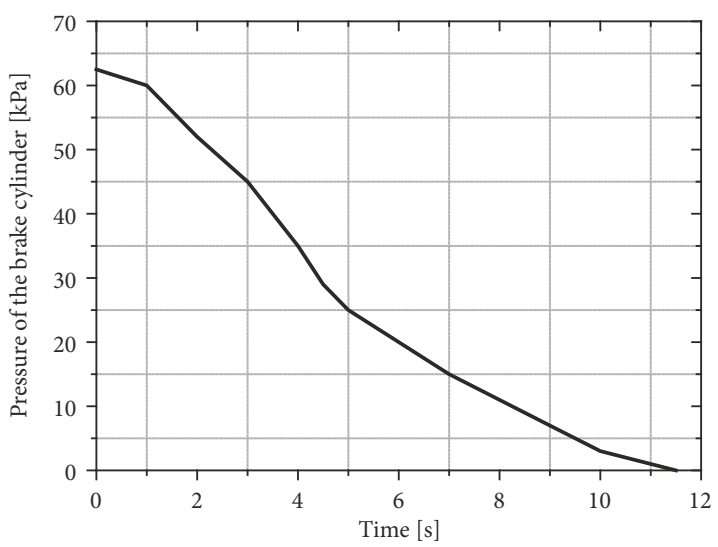

Figure 2. Pressure variation in the brake cylinder corresponding: a $-140 \mathrm{kPa}$ pressure reduction used in regular train braking; $\mathrm{b}-50 \mathrm{kPa}$ pressure reduction used in cyclic braking; $\mathrm{c}$ - release characteristic of the train in cyclic braking

\subsubsection{Characteristics of coupler buffer device}

In consideration of the characteristics of heavy haul train, the No 17 chain-fixed coupler and the MT-2 type buffer are adopted in the model.

Figure 3 shows the characteristic curve of resistant force vs displacement for the MT-2 type buffer after linear fitting. The dynamic characteristic curve of buffer forcedisplacement can be determined by the envelope of multiple results obtained in the drop hammer tests at different heights. The characteristic curve takes into account factors such as the coupler clearance and the initial pressure of the buffer, and can be used to describe the loading and unloading processes. The loading impedance character- 


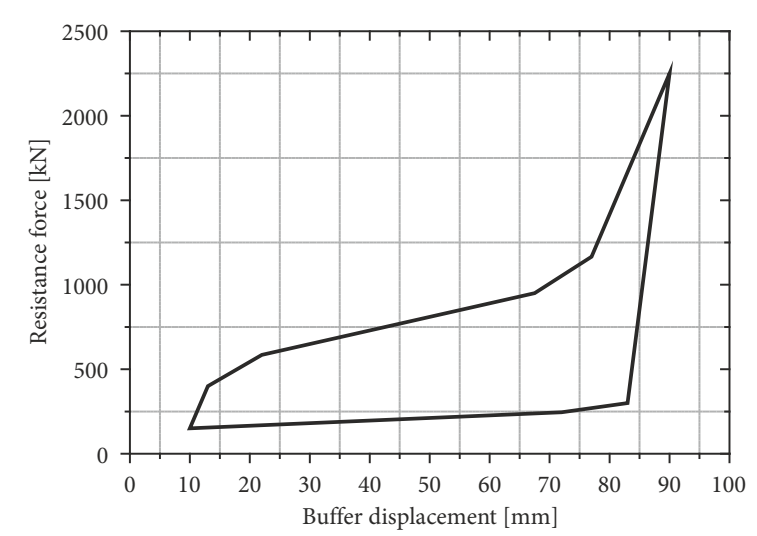

Figure 3. Dynamic model of the MT-2 type buffer - resistance force vs buffer displacement

istic curve is not consistent with the unloading impedance characteristic curve in this figure, demonstrating the properties of nonlinear hysteresis.

\subsubsection{Track resistance model}

The unit basic resistance of a running HXD1 locomotive is calculated by (Wu et al. 2016):

$$
w_{0}^{\prime}=1.4+0.0038 \cdot v+0.0003 \cdot v^{2}
$$

for the $\mathrm{C} 96$ freight car, the formula is:

$$
w_{0}^{\prime \prime}=0.92+0.0048 \cdot v+0.000126 \cdot v^{2},
$$

where: $w_{0}^{\prime}$ is the unit basic resistance of the running locomotive $[\mathrm{N} / \mathrm{kN}] ; w_{0}^{\prime \prime}$ is the unit basic resistance of the running freight car $[\mathrm{N} / \mathrm{kN}]$.

When the length of the train is less than or equal to the length of the curve, the unit curve additional resistance of the freight train is:

$$
\omega_{r}=\frac{600}{R} \cdot g \text {, }
$$

or the unit curve additional resistance is:

$$
\omega_{r}=\frac{600}{R} \cdot \frac{l_{r}}{l_{l}} \cdot g
$$

where: $\omega_{r}$ is the curve additional resistance $[\mathrm{N} / \mathrm{t}] ; R$ is the curve radius $[\mathrm{m}] ; g$ is the gravitational acceleration $\left[\mathrm{m} / \mathrm{s}^{2}\right]$; $l_{r}$ is the length of the curve $[\mathrm{m}] ; l_{l}$ is the length of the train $[\mathrm{m}]$.

\subsection{Energy composition and calculation method}

In the operation of heavy haul train, 8 different forms of energy are involved:

- locomotive tractive energy $E_{T}$;

- locomotive braking energy consumption $E_{D}$;

- basic resistive energy consumption $E_{p}$;

- curve induced additional resistance energy consumption $E_{C}$;

- air braking energy consumption $E_{A}$;

- gravitational potential energy $E_{G}$;

- kinetic energy of the train $E_{K}$;

- coupler-buffer device energy consumption $E_{D G}$.
The law of energy conservation is observed in the running of heavy haul train, i.e.:

$$
\begin{aligned}
& E_{T}=\left(E_{K 2}-E_{K 1}\right)+\left(E_{G 2}-E_{G 1}\right)+ \\
& E_{D}+E_{P}+E_{C}+E_{A}+E_{D G} .
\end{aligned}
$$

According to ref (Wu et al. 2014a, 2014b), the energy consumed by the coupler-buffer device constitutes a small proportion of the total energy consumption $\left(2.79 \cdot 10^{-5} \%\right)$, so it can be ignored in the calculation of energy consumption. The curve-induced additional resistance is small when the train is running, so it is not considered either. Therefore, the forms of energy considered in this paper only include the locomotive tractive energy $E_{T}$, locomotive braking energy consumption $E_{D}$, basic resistive energy consumption $E_{p}$, air braking energy consumption $E_{A}$, gravitational potential energy $E_{G}$, and kinetic energy of the train $E_{K}$.

The first five forms of energy are calculated according to the work done by the force. Assume that the internal force is constant at each calculation step, and then the formula is:

$$
E_{A}=\sum_{i=1}^{m} \sum_{j=1}^{n} f_{i j} \cdot \Delta s_{i j},
$$

where: $m$ is the total number of locomotive and vehicles; $n$ is the total number of calculation steps; $f_{i j}$ is the magnitude of internal force at a certain calculation step (median); $\Delta s_{i j}$ is the displacement deviation corresponding to each calculation step.

The kinetic energy can be calculated by:

$$
E=\sum_{i=1}^{n} \frac{m_{i} \cdot V_{i}^{2}}{2}
$$

where: $m_{i}$ is the mass of the $i$-th vehicle; $V_{i}$ is the velocity of the $i$-th vehicle.

The final formula calculating the energy consumption is:

$$
\begin{aligned}
& E_{T}=\left(E_{K 2}-E_{K 1}\right)+\left(E_{G 2}-E_{G 1}\right)+ \\
& E_{D}+E_{P}+E_{A} .
\end{aligned}
$$

\subsection{Model validation}

The proposed longitudinal dynamic model is validated by comparison of the coupler force computed with the proposed model and the results measured in the comprehensive test for heavy haul train on the Beijing-Guangzhou railway and the central south heavy haul railway of Shanxi. The train tested on the Beijing-Guangzhou railway is composed of $12 \mathrm{C} 64(\mathrm{H})$ - type freight cars, $12 \mathrm{C} 70$ or C70E - type freight cars, and 26 27-ton axle-load vehicles including flatcar, boxcar and tank car. This train is $753 \mathrm{~m}$ long, and is towed by a single locomotive providing 5000 -ton traction force. The coupler force of the 15-th bit is collected on site. The train tested on the central south heavy haul railway of Shanxi is composed of 100 C96-type freight cars, and the 12000-ton traction force is provided by two locomotives in the front and two at the end. 
Table 1. Measured and simulated results

\begin{tabular}{|c|c|c|c|c|}
\hline Measurement location & $\begin{array}{l}\text { Coupler } \\
\text { location }\end{array}$ & $\begin{array}{l}\text { Measured } \\
\text { result }[\mathrm{kN}]\end{array}$ & $\begin{array}{l}\text { Simulated } \\
\text { result }[\mathrm{kN}]\end{array}$ & Working condition \\
\hline \multirow{2}{*}{$\begin{array}{l}\text { The central south heavy haul railway } \\
\text { of Shanxi (flat, straight track) }\end{array}$} & 84 & 1525.2 & 1566.1 & \multirow{2}{*}{$\begin{array}{l}\text { Emergency initial braking speed } \\
70 \mathrm{~km} / \mathrm{h}\end{array}$} \\
\hline & 100 & -823.9 & -866.1 & \\
\hline \multirow{2}{*}{$\begin{array}{l}\text { The Beijing-Guangzhou railway (straight } \\
\text { downgrade with }-0.5 \% \text { slope gradient) }\end{array}$} & 15 & 350.8 & 373.8 & Regular initial braking speed $8.4 \mathrm{~km} / \mathrm{h}$ \\
\hline & 15 & 321.9 & 330.1 & Regular initial braking speed $5.8 \mathrm{~km} / \mathrm{h}$ \\
\hline
\end{tabular}

The coupler forces of the 84-th and 100-th bit are collected. Table 1 shows the comparison between the measured data and simulation results. The results calculated with the model are in good agreement with the test results, and the model is validated preliminarily.

\section{Results of heavy haul train running under downhill, cyclic braking conditions}

\subsection{Calculated working conditions}

The proposed model is used to analyse the longitudinal dynamic performance and energy consumption of a 10000-ton heavy haul train towed by two HXD1-type head locomotives with the " $1+1$ " form of composition. The grouping number of the C96-type freight car (with axle load of $30 \mathrm{t}$ ) is 84 ; the initial braking speed is $70 \mathrm{~km} / \mathrm{h}$ in the course of cyclic braking, the initial release speed is $40 \mathrm{~km} / \mathrm{h}$, and the maximum dynamic braking force of a single locomotive is $461 \mathrm{kN}$. The train is applied the maximum dynamic braking force when it is running under long-steep downgrades for the safety and the force acts on the locomotive.

The train is running on a downgrade with length of $10 \mathrm{~km}$ and gradient of $1 \ldots 13 \%$. According to the mechanical analysis, when the gradient is less than $5 \%$, the exertion of locomotive electric braking force will cause the train to slow down; therefore, only when the gradient is greater than $5 \%$, the locomotive electric braking provided by a single locomotive should be applied.

\subsection{Predicted longitudinal dynamic performance}

\subsubsection{Braking time and release time}

In the course of downhill cyclic braking, the operation status of heavy haul train is decided by the gradient of the longitudinal track profile and the braking performance of the train. The evaluation factors are the braking time and the release time (the release time is also called the time available for recharging) during cyclic braking. Too short recharging time for the train (less than $2 \mathrm{~min}$ ) will lead to insufficient recharging and affect the braking performance in the next cycle.

Table 2 shows the calculated braking time and release time during the cyclic braking of this heavy haul train for different slope gradients. With the increase of slope gradient, the braking time increases and the release time decreases rapidly; the exertion of locomotive electric braking force leads to salient increase in the release time but has small effect on the braking time. When the slope gradient is small, the release time is long, and the recharging requirements can be satisfied without the exertion of locomotive electric braking force. When the slope gradient is larger (greater than $10 \%$ ), the release time is almost close to $2 \mathrm{~min}$, so it is more secure to activate the locomotive electric braking simultaneously provided by two locomotives on continuous slopes with large gradients.

\subsubsection{Coupler force and acceleration}

In order to analyse the variation of longitudinal dynamic performance on downgrades with different gradients during cyclic braking, the coupler force and acceleration at different locations on the train (head vehicle, 20, 40, 60 and $80 \%$ total train length from the head, tail vehicle) running on downgrades with $1,5,8$ and $13 \%$ gradients are analysed in the course of cyclic braking.

Figure 4 shows the longitudinal dynamic performance of the train on a downgrade with $13 \%$ gradient. During a cycle, the coupler force and acceleration will fluctuate when the braking or release starts, and then reach their maximum values. With the completion of brake wave and release wave transmission, the fluctuations of the coupler force and acceleration tend to be stable. The coupler force decreases with the backward shift of coupler location, and owing to the existence of locomotive electric braking force, the train coupler is always in a state of compression. The coupler force of the head vehicle is always above

Table 2. Calculated results during cyclic braking of heavy haul train running on downgrades with different slope gradients

\begin{tabular}{|l|c|c|c|c|c|c|c|}
\hline Slope gradient [\%] & 0 & -1 & -2 & -3 & -4 & -5 & -6 \\
\hline Braking time & $1 \min 12 \mathrm{~s}$ & $1 \min 18 \mathrm{~s}$ & $1 \min 25 \mathrm{~s}$ & $1 \min 33 \mathrm{~s}$ & $1 \min 44 \mathrm{~s}$ & $1 \mathrm{~min} 56 \mathrm{~s}$ & $1 \mathrm{~min} 22 \mathrm{~s}$ \\
\hline Release time & - & - & $12 \min 32 \mathrm{~s}$ & $6 \min 56 \mathrm{~s}$ & $4 \min 48 \mathrm{~s}$ & $3 \min 40 \mathrm{~s}$ & $16 \mathrm{~min} 47 \mathrm{~s}$ \\
\hline Slope gradient [\%o] & -7 & -8 & -9 & -10 & -11 & -12 & -13 \\
\hline Braking time & $1 \min 30 \mathrm{~s}$ & $1 \min 40 \mathrm{~s}$ & $1 \min 52 \mathrm{~s}$ & $2 \min 7 \mathrm{~s}$ & $2 \min 26 \mathrm{~s}$ & $2 \min 54 \mathrm{~s}$ & $3 \min 6 \mathrm{~s}$ \\
\hline Release time & $8 \min 3 \mathrm{~s}$ & $5 \min 21 \mathrm{~s}$ & $3 \min 57 \mathrm{~s}$ & $3 \min 10 \mathrm{~s}$ & $2 \min 37 \mathrm{~s}$ & $2 \min 15 \mathrm{~s}$ & $2 \min 1 \mathrm{~s}$ \\
\hline
\end{tabular}


$400 \mathrm{kN}$, which is close to the locomotive electric braking force, but the coupler force of tail vehicle is very small, approximately 0 .

Table 3 gives the maximum coupler tensile and compressive forces of the train in downhill cyclic braking. In the entire cyclic braking, the coupler forces are much smaller than the calibration standard required for the Class-I special vehicles under the first working condition, $2000 \mathrm{kN}$ tensile force and $2250 \mathrm{kN}$ compression force. The accelerations are less than $10 \mathrm{~m} / \mathrm{s}^{2}$ and all within the safe limit.
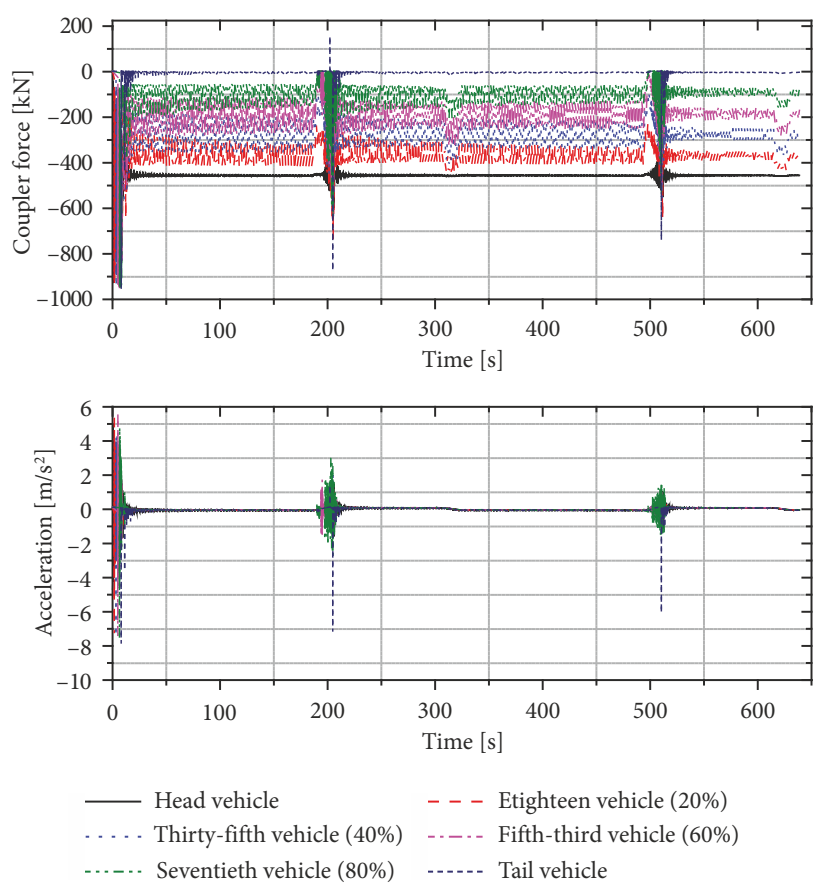

Figure 4. Coupler force and acceleration when the slope gradient is $-13 \%$ o

Table 3. Longitudinal dynamic performance of heavy haul train during cyclic braking

\begin{tabular}{|l|c|c|c|c|}
\hline Slope gradient [\%o] & -1 & -5 & -8 & -13 \\
\hline $\begin{array}{l}\text { Maximum coupler } \\
\text { force [kN] }\end{array}$ & -881.12 & -901.04 & -958.51 & -960.96 \\
\hline $\begin{array}{l}\text { Maximum coupler } \\
\text { force [kN] }\end{array}$ & 873.08 & 870.82 & 321.4 & 153.51 \\
\hline $\begin{array}{l}\text { Maximum positive } \\
\left.\text { acceleration [m/s } \mathrm{s}^{2}\right]\end{array}$ & 7.15 & 7.18 & 6.04 & 5.53 \\
\hline $\begin{array}{l}\text { Maximum negative } \\
\text { acceleration [m/s } \mathrm{s}^{2}\end{array}$ & -7.43 & -7.59 & -7.97 & -7.67 \\
\hline
\end{tabular}

\subsection{Predicted energy consumption}

Figure 5 shows the variation of energy consumption of the train running on downgrades with different slope gradients. The basic resistance energy consumption and locomotive braking energy consumption do not vary much. With the increase of slope gradient, the energy consumption of air braking tends to increase, and when the

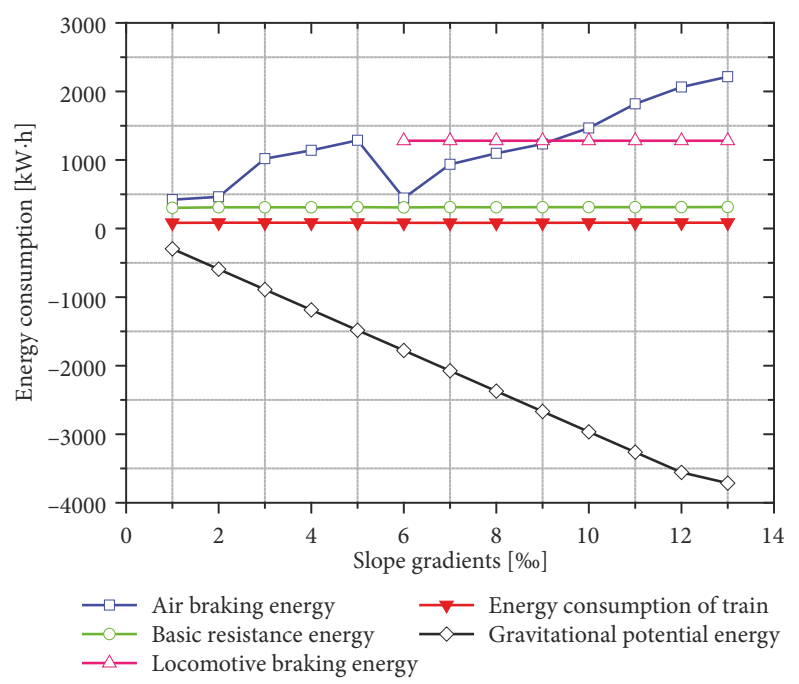

Figure 5. Energy consumption of train for different slope gradients

gradient is greater than $6 \%$, in order to ensure sufficient recharging, the locomotive braking force is applied, and then the braking distance of the train is reduced and the energy consumption of air braking is also greatly reduced. When the slope gradient is small, activation of the locomotive braking force can reduce the energy consumption of air braking; however, with the increase of slope gradient, the energy consumption of air braking will increase rapidly. In the course of cyclic braking of heavy haul train running downhill, the gravity does positive work, and the variation of gravitational potential energy can be used as a source of energy input to the train system, so the total energy consumption of the train is very small. With the increase of slope gradient, the braking energy consumption will increase, and the change of gravitational potential energy will increase accordingly; however, the basic resistance energy consumption and kinetic energy variation of the running train have not changed, so the total energy consumption is approximately constant.

Figure 6 shows the composition of energy consumption during cyclic braking of the training running on downgrades with different slope gradients. The braking energy consumption (including the air braking energy consumption and locomotive braking energy consumption) always constitutes the largest proportion of energy consumption, accounting for more than $50 \%$. When the slope gradient is small, the air braking energy consumption constitutes a larger proportion; after the locomotive braking force is applied, the locomotive braking energy consumption becomes the major part, and the proportion of the energy consumed by air braking is significantly reduced. With the increase of slope gradient, the braking distance increases, and the proportion of energy consumed by air braking increases and becomes the major component of the total energy consumption, while the proportion of basic resistance energy consumption decreases rapidly with the increase of slope gradient. 
a)

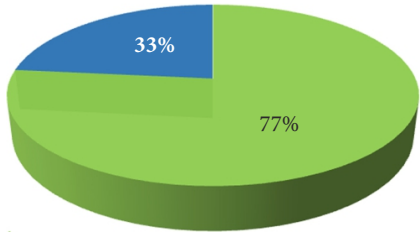

Air braking energy consumption b)

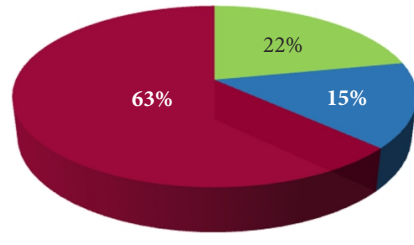

Basic resistance energy consumption c)

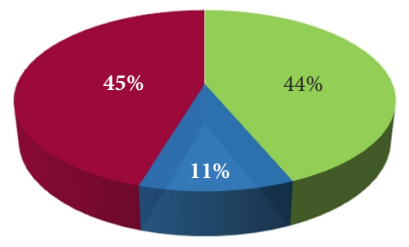

d)

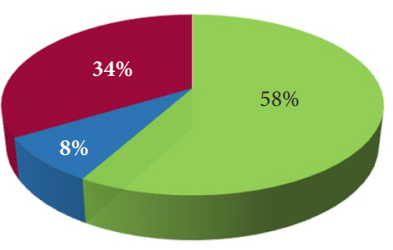

Figure 6. Composition of energy consumption of train during cyclic braking for different slope gradients: $\mathrm{a}-3 \%$; b - 6\%o; c- $9 \%$; d - $13 \%$ o

\section{Case study of the South Changzi station-South Shuizhi station segment}

\subsection{Engineering survey}

The most difficult segment in the design of the central south heavy haul railway of Shanxi is the Huguan-South Shuizhi long-steep downgrade more than $100 \mathrm{~km}$ long and with the maximum gradient of $13 \%$, as shown in Table 4. In order to include all the operating conditions of a running train, the longitudinal dynamics is simulated of a heavy haul train running on a $155 \mathrm{~km}$ long railway in the South Changzi station-South Shuizhi station segment.

The slope gradient and longitudinal profile of this segment are shown in Table 4 and Figure 7, respectively. A heavy haul train departs from the South Changzi station

Table 4. Slope gradients in the South Changzi station-South Shuizhi station segment

\begin{tabular}{|c|c|c|l|}
\hline $\begin{array}{c}\text { Mileage at } \\
\text { varied slope } \\
\text { gradient }\end{array}$ & $\begin{array}{c}\text { Designed } \\
\text { shoulder } \\
\text { elevation } \\
{[\mathrm{m}]}\end{array}$ & $\begin{array}{c}\text { Designed } \\
\text { slope } \\
\text { gradient } \\
{[\% \text { o }}\end{array}$ & Annotations \\
\hline D1K484+400.00 & 948.80 & 0.00 & $\begin{array}{l}\text { The South } \\
\text { Changzi station }\end{array}$ \\
\hline DK494+500.00 & 991.23 & 5.00 & \\
\hline DK495+150.00 & 994.48 & -3.00 & \\
\hline DK496+000.00 & 988.73 & -13.00 & \\
\hline DK503+400.00 & 995.27 & 5.20 & \\
\hline DK523+700.00 & 1021.19 & -4.00 & \\
\hline DK525+600.00 & 1020.09 & 2.10 & \\
\hline DK526+700.00 & 1020.19 & -1.00 & $\begin{array}{l}\text { The Huguan } \\
\text { station }\end{array}$ \\
\hline DK529+500.00 & 1016.04 & -13.00 & \\
\hline DK537+500.00 & 952.57 & 3.50 & \\
\hline DK543+100.00 & 908.11 & -13.00 & \\
\hline DK597+500.00 & 353.97 & 6.00 & \\
\hline D1K601+050.00 & 357.87 & -9.00 & \\
\hline D1K602+330.00 & 344.81 & 1.00 & \\
\hline D1K610+100.00 & 324.81 & -13.00 & \\
\hline DK615+930.00 & 279.14 & 3.00 & \\
\hline DK617+600.00 & 281.45 & -13.00 & \\
\hline DK631+750.00 & 123.77 & -1.00 & The South \\
Shuizhi station \\
\hline
\end{tabular}

(elevation $948.8 \mathrm{~m}$ ), goes through an upgrade about $45 \mathrm{~km}$ long, and reaches the highest point in this segment - the Huguan station (elevation $1020.19 \mathrm{~m}$ ). The train then enters into the long-steep downgrade (about $100 \mathrm{~km}$ long) in the Huguan station-South Shuizhi station segment and cyclic braking is applied. Finally, the train is decelerated by full braking to $0 \mathrm{~m} / \mathrm{s}$ and stops at the South Shuizhi station (elevation $123.77 \mathrm{~m}$ ). The whole-course elevation difference is up to $896.42 \mathrm{~m}$.

\subsection{Predicted longitudinal dynamic performance}

The simulated train has the same formation as in Section 3. When running in the South Zhangzi station-South Shuizhi station segment, the train will undergo four stages: "starting $\rightarrow$ constant velocity $\rightarrow$ cycle braking $\rightarrow$ full braking". Figure 8 shows the time history curve of the locomotive speed. In the whole course of train operation, the train speed is between $35 \ldots 75 \mathrm{~km} / \mathrm{h}$ and can meet the speed limit.

\subsubsection{Braking time and release time}

Table 5 shows the calculated results for the braking and releasing processes. A total of 14 complete cycles of braking are applied. The braking time is less than $3 \mathrm{~min}$, and the release time is above $2 \mathrm{~min}$, so the train has good braking and release performance, and the recharging requirement can be satisfied in this segment.

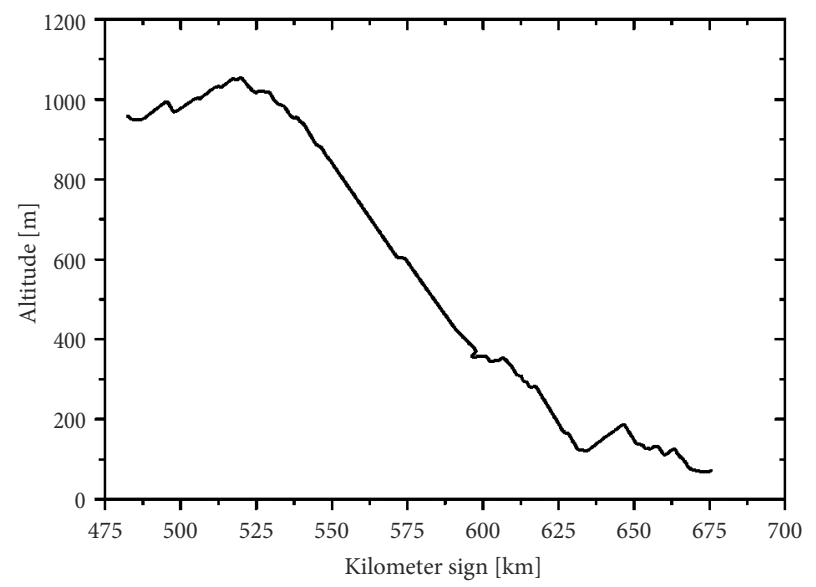

Figure 7. Contracted longitudinal profile of the South Changzi station-South Shuizhi station segment 


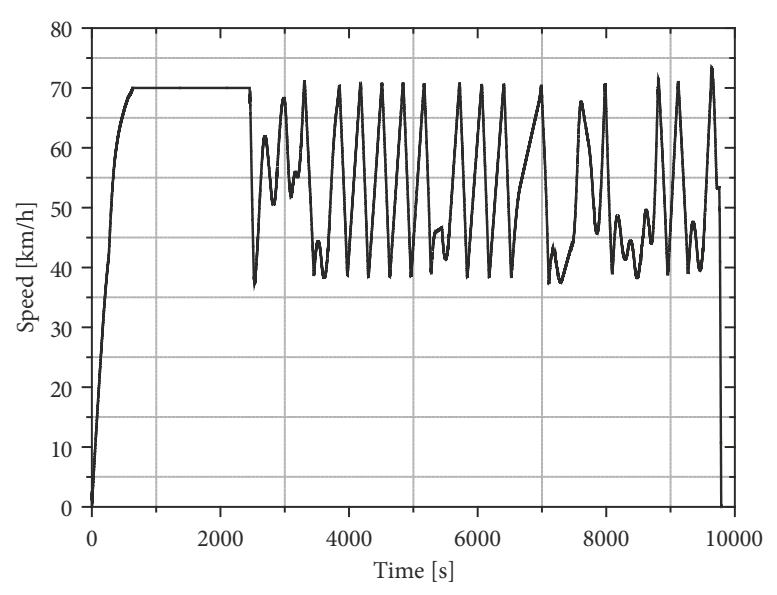

Figure 8. Time history of velocity in the South Changzi station-South Shuizhi station segment

Table 5. Simulated results for cyclic braking

\begin{tabular}{|c|c|c|c|c|}
\hline $\begin{array}{c}\text { Number of } \\
\text { cycles of } \\
\text { braking }\end{array}$ & $\begin{array}{c}\text { Braking } \\
\text { time }\end{array}$ & $\begin{array}{c}\text { Time } \\
\text { available for } \\
\text { recharging }\end{array}$ & $\begin{array}{c}\text { Initial } \\
\text { braking } \\
\text { speed } \\
{[\mathrm{km} / \mathrm{h}]}\end{array}$ & $\begin{array}{c}\text { Initial } \\
\text { release } \\
\text { speed } \\
{[\mathrm{km} / \mathrm{h}]}\end{array}$ \\
\hline 1 & $1 \min 1 \mathrm{~s}$ & $13 \min 3 \mathrm{~s}$ & 70 & 40 \\
\hline 2 & $2 \min 28 \mathrm{~s}$ & $6 \min 37 \mathrm{~s}$ & 70 & 40 \\
\hline 3 & $2 \min 3 \mathrm{~s}$ & $3 \min 26 \mathrm{~s}$ & 70 & 40 \\
\hline 4 & $2 \min$ & $3 \min 32 \mathrm{~s}$ & 70 & 40 \\
\hline 5 & $2 \min 1 \mathrm{~s}$ & $3 \min 28 \mathrm{~s}$ & 70 & 40 \\
\hline 6 & $2 \min 2 \mathrm{~s}$ & $3 \min 25 \mathrm{~s}$ & 70 & 40 \\
\hline 7 & $1 \min 47 \mathrm{~s}$ & $7 \min 24 \mathrm{~s}$ & 70 & 40 \\
\hline 8 & $1 \min 58 \mathrm{~s}$ & $3 \min 47 \mathrm{~s}$ & 70 & 40 \\
\hline 9 & $1 \min 54 \mathrm{~s}$ & $3 \min 50 \mathrm{~s}$ & 70 & 40 \\
\hline 10 & $1 \min 54 \mathrm{~s}$ & $7 \min 49 \mathrm{~s}$ & 70 & 40 \\
\hline 11 & $1 \min 54 \mathrm{~s}$ & $14 \min 41 \mathrm{~s}$ & 70 & 40 \\
\hline 12 & $1 \min 48 \mathrm{~s}$ & $11 \min 56 \mathrm{~s}$ & 70 & 40 \\
\hline 13 & $2 \min 27 \mathrm{~s}$ & $2 \min 41 \mathrm{~s}$ & 70 & 40 \\
\hline 14 & $2 \min 37 \mathrm{~s}$ & $6 \min 1 \mathrm{~s}$ & 70 & 40 \\
\hline
\end{tabular}

\subsubsection{Coupler force and acceleration}

In order to analyse the coupler force and acceleration at different locations of the train, the coupler force and acceleration are analysed at different locations of the train (head vehicle, 20, 40, 60 and $80 \%$ total train length from the head, tail vehicle). The calculated results are shown in Figures 9 and 10. The coupler force and acceleration display a wide range of fluctuations when the braking and the release start. With the backward shift of coupler location, the coupler force gradually decreases and the coupler force at the end of the train is very small, close to 0 . The maximum coupler tensile force is $921.65 \mathrm{kN}$, the maximum coupler compressive force is $1039.64 \mathrm{kN}$, the maximum positive acceleration is $7.63 \mathrm{~m} / \mathrm{s}^{2}$, and the maximum negative acceleration is $-8.59 \mathrm{~m} / \mathrm{s}^{2}$. The couple tensile and compressive forces are far less than the required coupler calibration standards for the Class-I special vehicles under

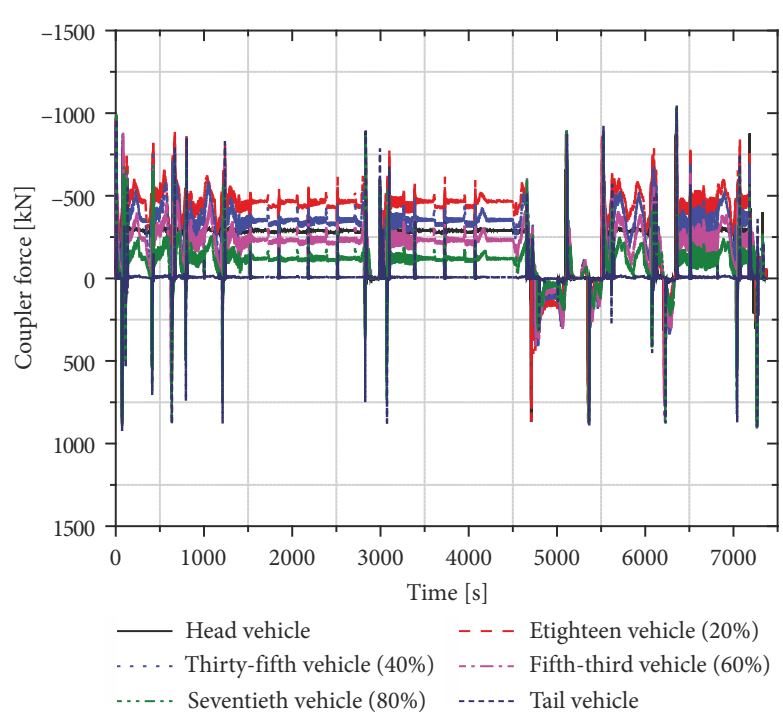

Figure 9. Time history of coupler force in the course of cyclic braking

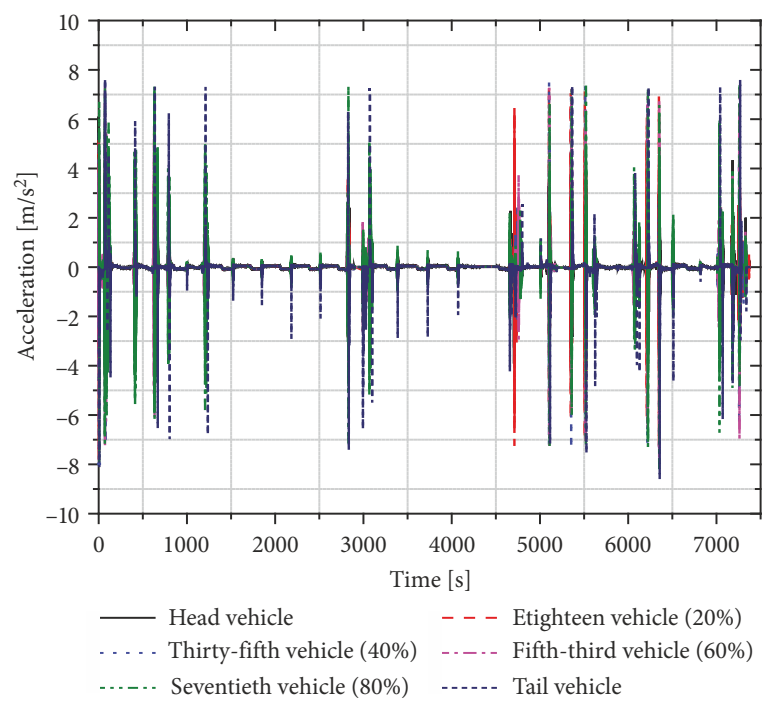

Figure 10. Time history of acceleration in the course of cyclic braking

the first working condition: $2000 \mathrm{kN}$ and $2250 \mathrm{kN}$, respectively, and the acceleration is less than the recommended level of $10 \mathrm{~m} / \mathrm{s}^{2}$ according to the safety control standard.

\subsection{Predicted operational energy consumption}

In the South Changzi station-South Shuizhi station segment, the energy source is the gravitational potential energy and locomotive traction energy, and the energy is mainly consumed by air braking, locomotive braking, and the basic resistance. Figure 11 shows the time history of energy consumption in the course of cyclic braking. The kinetic energy has the same trend of variation as the speed shown in Figure 8. The basic resistance energy consumption, air braking energy consumption and locomotive braking energy consumption continue to increase with time, but the basic resistance energy consumption is far less than the latter two forms of energy consumption 


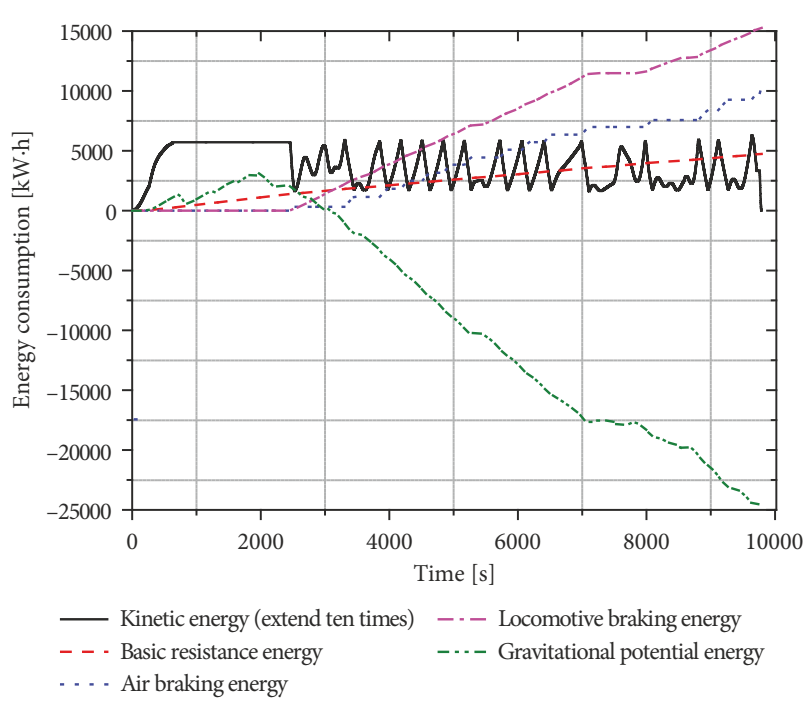

Figure 11. Time history of energy consumption in the course of cyclic braking

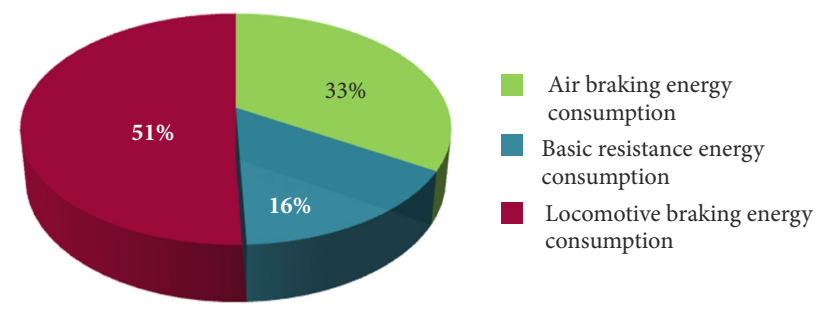

Figure 12. Composition of energy consumption in the course of cyclic braking

(also called the braking energy consumption). The gravitational potential energy first increases and then decreases, and shows a generally decreasing trend, because the segment profile is first upgrade and then downgrade, and the downgrade is the dominant part.

Figure 12 shows the composition of energy consumption in the same course. Because of the dominant longsteep downgrade in the segment, the major component is the braking energy consumption, accounting for more than $80 \%$ of the total energy consumption. The locomotive braking force exists in the entire braking process, so the locomotive braking energy consumption accounts for more than $50 \%$ of the total energy consumption, while the basic resistance energy consumption accounts for only $16 \%$ of the total energy consumption.

\section{Conclusions}

In this paper, a dynamic model is proposed to predict the longitudinal dynamic performance of a heavy haul train running on long-steep downgrades, and based on the model, methods of calculating the energy consumption are also proposed. The following conclusions are drawn:

1) To ensure sufficient time for recharging under the condition of downhill cyclic braking, electropneumatic blended braking is required. With the increase of slope gradient, the braking time in- creases and the release time decreases. When the slope gradient is greater than $10 \%$, the locomotive braking force provided by one locomotive will lead to almost 2 min release time;

2) The gravitational potential energy is the main energy source for heavy haul trains running on long-steep downgrades, and the total energy consumption of the train is far less than the locomotive traction energy consumption in the course of uphill traction; in the course of cyclic braking, the braking energy consumption always accounts for a large proportion of the total energy consumption (more than 50\%);

3) The model is used to simulate a total of 14 full cycles of braking on the long-steep downgrade in the South Changzi station-South Shuizhi station segment in central south heavy haul railway of Shanxi. The results show that the braking time is less than $3 \mathrm{~min}$ and the release time is longer than $2 \mathrm{~min}$; such good braking performance can satisfy the recharging requirements. When a train is running in this segment, the maximum coupler tensile force will be $921.65 \mathrm{kN}$, and the maximum coupler compressive force will be $1039.64 \mathrm{kN}$, far less than the coupler calibration standards required for the ClassI special vehicles under the first working condition: 2000 and $2250 \mathrm{kN}$, respectively. The total energy consumption in this segment is $5614.22 \mathrm{kWh}$, and the braking energy consumption accounts for more than $80 \%$ of the total energy consumption.

\section{Acknowledgements}

This work was supported by the National Natural Science Foundation of China under Grant [number 51578054].

\section{References}

Afshari, A.; Specchia, S.; Shabana, A. A.; Caldwell, N. 2013. A train air brake force model: car control unit and numerical results, Proceedings of the Institution of Mechanical Engineers, Part F: Journal of Rail and Rapid Transit 227(1): 38-55. https://doi.org/10.1177/0954409712447231

Belforte, P.; Cheli, F.; Diana, G.; Melzi, S. 2008. Numerical and experimental approach for the evaluation of severe longitudinal dynamics of heavy freight trains, Vehicle System Dynamics: International Journal of Vehicle Mechanics and Mobility 46: 937-955. https://doi.org/10.1080/00423110802037180

Chang, C.; Guo, G.; Wang, J.; Ma, Y. 2017. Study on longitudinal force simulation of heavy-haul train, Vehicle System Dynamics: International Journal of Vehicle Mechanics and Mobility 55(4): 571-582. https://doi.org/10.1080/00423114.2016.1269183

Cole, C.; Sun, Y. Q. 2006. Simulated comparisons of wagon coupler systems in heavy haul trains, Proceedings of the Institution of Mechanical Engineers, Part F: Journal of Rail and Rapid Transit 220(3): 247-256. https://doi.org/10.1243/09544097JRRT35

Conti, R.; Galardi, E.; Meli, E.; Nocciolini, D.; Pugi, L.; Rindi, A. 2015. Energy and wear optimisation of train longitudinal dynamics and of traction and braking systems, Vehicle System 
Dynamics: International Journal of Vehicle Mechanics and Mobility 53(5): 651-671.

https://doi.org/10.1080/00423114.2014.990466

Lebedevas, S.; Dailydka, S.; Jastremskas, V.; Rapalis, P. 2017. Research of energy efficiency and reduction of environmental pollution in freight rail transportation, Transport 32(3): 291301. https://doi.org/10.3846/16484142.2016.1230888

Murtaza, M. A. 1993. Railway air brake simulation: an empirical approach, Proceedings of the Institution of Mechanical Engineers, Part F: Journal of Rail and Rapid Transit 207(1): 51-56. https://doi.org/10.1243/PIME_PROC_1993_207_226_02

Piechowiak, T. 2009. Pneumatic train brake simulation method, Vehicle System Dynamics: International Journal of Vehicle Mechanics and Mobility 47(12): 1473-1492.

https://doi.org/10.1080/00423110802600946

Piechowiak, T. 2010. Verification of pneumatic railway brake models, Vehicle System Dynamics: International Journal of Vehicle Mechanics and Mobility 48(3): 283-299. https://doi.org/10.1080/00423110902780622

Pugi, L.; Palazzolo, A.; Fioravanti, D. 2008. Simulation of railway brake plants: an application to SAADKMS freight wagons, Proceedings of the Institution of Mechanical Engineers, Part F: Journal of Rail and Rapid Transit 222(4): 321-329. https://doi.org/10.1243/09544097JRRT118

Pugi, L.; Rindi, A.; Ercole, A. G.; Palazzolo, A.; Auciello, J.; Fioravanti, D.; Ignesti, M. 2011. Preliminary studies concerning the application of different braking arrangements on Italian freight trains, Vehicle System Dynamics: International Journal of Vehicle Mechanics and Mobility 49(8): 1339-1365. https://doi.org/10.1080/00423114.2010.505291

Sun, Y.; Cole, C.; Spiryagin, M.; Godber, T.; Hames, S.; Rasul, M. 2014. Longitudinal heavy haul train simulations and energy analysis for typical Australian track routes, Proceedings of the Institution of Mechanical Engineers, Part F: Journal of Rail and Rapid Transit 228(4): 355-366.

https://doi.org/10.1177/0954409713476225

Wei, W.; Hu, Y.; Wu, Q.; Zhao, X.; Zhang, J.; Zhang, Y. 2017. An air brake model for longitudinal train dynamics studies, Vehicle System Dynamics: International Journal of Vehicle Mechanics and Mobility 55(4): 517-533.

https://doi.org/10.1080/00423114.2016.1254261

Wei, W.; Lin, Y. 2009. Simulation of a freight train brake system with 120 valves, Proceedings of the Institution of Mechanical Engineers, Part F: Journal of Rail and Rapid Transit 223(1): 85-92. https://doi.org/10.1243/09544097JRRT119

Wu, Q.; Cole, C.; Luo, S.; Spiryagin, M. 2014a. A review of dynamics modelling of friction draft gear, Vehicle System Dynamics: International Journal of Vehicle Mechanics and Mobility 52(6): 733-758.

https://doi.org/10.1080/00423114.2014.894199

Wu, Q.; Luo, S.; Cole, C. 2014b. Longitudinal dynamics and energy analysis for heavy haul trains, Journal of Modern Transportation 22(3): 127-136.

https://doi.org/10.1007/s40534-014-0055-X

Wu, Q.; Luo, S.; Qu, T.; Yang, X. 2017. Comparisons of draft gear damping mechanisms, Vehicle System Dynamics: International Journal of Vehicle Mechanics and Mobility 55(4): 501-516. https://doi.org/10.1080/00423114.2016.1252049

Wu, Q.; Spiryagin, M.; Cole, C. 2015. Advanced dynamic modelling for friction draft gears, Vehicle System Dynamics: International Journal of Vehicle Mechanics and Mobility 53(4): 475-492. https://doi.org/10.1080/00423114.2014.1002504
Wu, Q.; Spiryagin, M.; Cole, C. 2016. Longitudinal train dynamics: an overview, Vehicle System Dynamics: International Journal of Vehicle Mechanics and Mobility 54(12): 1688-1714. https://doi.org/10.1080/00423114.2016.1228988 